\title{
Central Precocious Puberty in an Infant with Sotos Syndrome and Response to Treatment
}

\author{
(D) Tuğba Kontbay¹, (D) Zeynep Şıklar², (D) Serdar Ceylaner³, (D) Merih Berberoğlu² \\ 1Şanlıurfa Training and Research Hospital, Clinic of Pediatric Endocrinology, Şanlıurfa, Turkey \\ 2Ankara University Faculty of Medicine, Department of Pediatric Endocrinology, Ankara, Turkey \\ 3 Intergen Genetic Center, Ankara, Turkey
}

\begin{abstract}
What is already known on this topic?
Sotos syndrome (SS) is characterized by overgrowth, typical facial appearance, and learning disability. While advanced bone age can be detected in some cases, precocious puberty (PP) has only been reported in three cases previously.
\end{abstract}

\section{What this study adds?}

In some specific syndromes with PP, such as SS, treatment can be difficult. Maximum dose gonadotropin releasing hormone analog may not be successful for the control of pubertal progression. Cyproterone acetate may be beneficial for treatment.

\begin{abstract}
Sotos syndrome (SS) is characterized by overgrowth, distinctive facial appearance, and learning disability. It is caused by heterozygous mutations, including deletions of NSD1 located at chromosome 5q35. While advanced bone age can occur in some cases, precocious puberty (PP) has only been reported in three cases previously. Here, we reported a case of SS diagnosed in the infancy period with central PP. The discovery of potential factors that trigger puberty is one of the central mysteries of pubertal biology. Depot gonadotropinreleasing hormone analogs constitute the first-line therapy in central PP (CPP), which has proven to be both effective and safe. In our cases, leuprolide acetate at maximum dose was not successful in controlling pubertal progression, and cyproterone acetate (CPA) was added to therapy, with successful control of pubertal progression. In some specific syndromes with PP, such as SS, treatment can be challenging. CPA may be an asset for effective treatment.
\end{abstract}

Keywords: Sotos syndrome, precocious puberty, NSD1, cyproterone acetate

\section{Introduction}

Sotos syndrome (SS) is a rare syndrome with an incidence of approximately 1 in 14,000 live births (1). This childhood overgrowth syndrome of prenatal onset is characterized by increased birth length or head circumference, typically greater than two standard deviations from the mean, distinctive facial features, excessive growth during the first four years, and advanced bone age. Children with SS have macrodolichocephaly, broad and prominent forehead, and bitemporal narrowing (2). Also, they may present with neonatal hypotonia, delays in motor development and intellectual disabilities (2). The majority of cases have a mutation in the nuclear receptor-binding SET domain- containing protein 1 gene (NSD1), which are mostly de novo (3). SS results from loss of function mutations, primarily truncating mutations, and whole gene deletions $(1,4,5)$. The four major diagnostic criteria were based on the systematic assessment of 41 typical cases and include overgrowth with advanced bone age, macrocephaly, distinctive facial appearance, and learning difficulties. Features of this syndrome were re-evaluated after the identification of NSD1 mutations, and the Childhood Overgrowth Collaboration Consortium reviewed the clinical features of cases with NSD1 abnormalities (6).

Several endocrine problems may occur in SS (7). While advanced bone age can be detected in some cases, 
precocious puberty (PP) has only been reported in three cases until now, and the reason for PP remains unknown $(8,9,10)$. Also, long term follow-up characteristics and response to treatment had not been discussed in the literature. Here, we reported a case of SS associated with central PP (CPP) and the difficulties of clinical management.

\section{Case Report}

A 6.5 month-old male infant presented with neuromotor delay and macrogenitalia. He was the second child of nonrelated parents, and his birth-weight was $4200 \mathrm{~g}$. There were no other pathological features on physical examination, except for height which was $81 \mathrm{~cm}$ (SDS +5.6), testicular volumes of $4 \mathrm{~mL}$ bilaterally, and penis length of $6.7 \mathrm{~cm}$. Mild facial dysmorphism with global developmental delay was noted. High basal testosterone level ( $88 \mathrm{ng} / \mathrm{dL}$ ), and high basal and stimulated gonadotropins (basal luteinizing hormone [LH] $1.56 \mathrm{mIU} / \mathrm{mL}$, basal follicle-stimulating hormone [FSH] $1.02 \mathrm{mIU} / \mathrm{mL}$, stimulated $\mathrm{LH} 43.3 \mathrm{mIU} /$ $\mathrm{mL}$, and stimulated FSH $3.65 \mathrm{mIU} / \mathrm{mL}$ ) confirmed the CPP. Cranial imaging studies revealed normal pituitary gland with dilated perivascular cavities in subcortical white matter, dilatation of cerebral lateral ventricles, and cavum septum pellucidum. The patient's bone age was found to be oneyear-old.

Gonadotropin releasing hormone $(\mathrm{GnRH})$ analog at a dose of $250 \mathrm{mcg} / \mathrm{kg} / \mathrm{month}$ was started. Due to inefficient hypothalamic-pituitary-gonadal (HHG) axis control, the GnRH analog dose was increased to $500 \mathrm{mcg} / \mathrm{kg} / \mathrm{month}$. At the age of 2.5 years an increase of testicular volume to 8 $\mathrm{mL}$ and penile length to $9 \mathrm{~cm}$ was observed, and his bone age had advanced to 4.5 years after 20 months of treatment with GnRH analog. The basal LH level was $1.6 \mathrm{mIU} / \mathrm{mL}$, and the basal testosterone level $58 \mathrm{ng} / \mathrm{dL}$. Due to continued pubertal progression and unsuccessful suppression of $\mathrm{LH}$ and testosterone level, cyproterone acetate (CPA) $50 \mathrm{mg} /$ day was added to his treatment. Over the next three years with combined treatment, the patient's clinical and laboratory progression was controlled. At the last examination, he was 6.24 years old, and his height was $139 \mathrm{~cm}$ [standard deviation score (SDS) + 4.52]. The patient's testicular volume regressed to $5 \mathrm{~mL}$, and basal testosterone level was suppressed to prepubertal level. Laboratory results of the patient before and during treatment are shown in Table 1 .

As his phenotype resembled SS, NSD1 analysis was performed, and a heterozygous mutation NM_022455.4: c. $5177 \mathrm{C}>\mathrm{G}$ (p.Pro1726Arg) was detected. This variant was not found in gnomAD exomes and gnomAD genomes. There are several other pathogenic mutations very near this codon in this gene. Pathogenic computational results were based on 12 pathogenic predictions from BayesDel_ addAF, DANN, DEOGEN2, EIGEN, FATHMM-MKL, M-CAP, MVP, MutationAssessor, MutationTaster, PrimateAI, REVEL and SIFT versus no benign predictions. ClinVar classified this variant as Pathogenic. Thus this variant was evaluated as pathogenic due to the American College of Medical Genetics criteria. Informed consent was received from his parents.

\section{Discussion}

SS is characterized by overgrowth and typical facial features, but other clinical features and their molecular bases have been identified as well. Additional features may be present, potentially as a consequence of micro-deletions encompassing other genes in addition to NSD1 $(11,12)$. Our patient was large for his gestational age (birth weight was $4200 \mathrm{~g}$, gestation age was normal). He had distinctive facial features with macrodolichocephaly, marked frontal bossing, with a long and thin face in addition to global developmental delay. While CPP was the most striking feature of the patient, other clinical characteristics were compatible with SS. He was clinically considered SS, then NSD1 analysis was performed, and a heterozygous mutation NM_022455.4: c.5177C > G (p.Pro1726Arg) was detected.

Many benign and pathogenic variants of NSD1 have been identified. However, the mechanismof functional abrogation

\begin{tabular}{|c|c|c|c|c|c|c|}
\hline Age (year) & $\begin{array}{l}\text { Basal LH } \\
(\mathrm{mIU} / \mathrm{mL})\end{array}$ & $\begin{array}{l}\text { Basal FSH (mIU/ } \\
\mathrm{mL})\end{array}$ & $\begin{array}{l}\text { Testosterone } \\
(\mathrm{ng} / \mathrm{dL})\end{array}$ & $\begin{array}{l}\text { Peak LH } \\
(\mathrm{mIU} / \mathrm{mL})\end{array}$ & $\begin{array}{l}\text { Peak FSH } \\
(\mathrm{mIU} / \mathrm{mL})\end{array}$ & Treatment \\
\hline 0.6 & 1.02 & 1.56 & 88 & 43.3 & 3.65 & GnRH a (250 mcg/kg/month) \\
\hline 1.28 & 3.52 & 0.39 & 67 & 6 & 0.54 & GnRH a (500 mcg/kg/month) \\
\hline 2.5 & 1.61 & 0.13 & 58 & 6.5 & 0.53 & $\begin{array}{l}\text { GnRH a (500 } \mathrm{mcg} / \mathrm{kg} / \mathrm{month}) \\
+ \\
\text { Cyproterone acetate }\end{array}$ \\
\hline
\end{tabular}


of NSD1 resulting in SS remains unknown. It is thought that there may be a link between SS and rat sarcoma-mitogenactivated protein kinase (RAS-MAPK) signaling pathway, which is downregulated in SS (13). RAS-MAPK pathway is also known as the Ras-Raf-MEK-ERK (MAPK/ERK). However, Ras interacting protein 1, a downstream Ras effector interfering with the MAPK/ERK pathway, is identified as being upregulated in SS (14). The deregulation of the MAPK/ ERK-signaling cascade causes a hypertrophic differentiation of NSD1-expressing chondrocytes with subsequent statural overgrowth and accelerated skeletal maturation in patients with SS (14).

Our case presented with CPP at a very early age. CPP in SS is an infrequent finding, although some endocrine problems such as hypoglycemia, hypothyroidism, hypospadias, and cryptorchidism in infancy have been reported (7).

Cases such as ours, caused by central activation of the HHG axis are referred to as CPP, the etiology of which can be idiopathic, familial, or secondary to structural brain anomalies $(15,16)$. CPP may have critical underlying causes, including acquired and congenital central nervous system (CNS) lesions or congenital causes without CNS lesions, such as complex syndromic phenotypes with or without known chromosomal abnormalities or genetic changes. Most of the time, the common cause of CPP in females is idiopathic, while in males, there is usually an underlying pathology. CPP may develop in infancy in male patients with an organic lesion (17).

For SS, only three cases with PP have been reported to date in the literature $(8,9,10)$. The first case with CPP of SS was reported in 1995. Although we could not obtain detailed information about this case, she was reported to have premature pubarche and premature pubertal development (8). The second case was presented at the European Society for Paediatric Endocrinology meeting in 2016. He was diagnosed at 6.8 years of age with CPP with a global developmental delay. NSD1 gene deletion was found after the diagnosis of PP. This case had normal pituitary and brain magnetic resonance imaging (MRI) (9). The third case was a 3-month-old boy, reported by Gupta and Dayal (10), who presented with enlargement of genitalia and rapid growth noticed since birth and was diagnosed with CPP and SS. Genetic analysis identified a pathogenic heterozygous mutation in the NSD1 gene (c.2362C > T; p. Arg788Ter).

The pathogenesis of CPP is not yet fully understood in this syndrome. Some structural brain abnormalities, which usually develop in SS, might induce CPP by activating the HHG axis. In our patient, cranial MRI revealed brain formation anomalies (dilatation of cerebral lateral ventricles and cavum septum pellucidum), but the hypothalamus and hypophysis were normal. However, the cause of CPP may not be related to such cranial structural abnormalities since not all SS cases have CPP despite having similar cranial imaging features. A disorder of the central activation of the HHG axis is likely, although the underlying pathophysiological mechanism is not yet determined (13).

Many factors that regulate the timing of puberty remains unclear, despite recent advances. Some syndromes associated with disorders of pubertal timing provide opportunities to identify genetic regulation of puberty. RASopathies are developmental disorders caused by heterozygous activating germline mutations in RASMAPK pathway genes. The RAS-MAPK pathway, also known as the Ras-Raf-MEK-ERK pathway, plays a central role in signal transduction from extracellular stimuli to the intracellular environment $(18,19)$. The RAS-MAPK pathway is one of the pathways involved in the regulation of the GnRH receptor signaling cascades. GnRH receptor signaling results in the secretion of LH and FSH. Therefore, genetic abnormalities in this pathway could hypothetically lead to either delayed or PP development. Although, as with PP, this association's exact etiology is not fully understood (20). It can be suggested that CPP in SS may be associated with these RAS-MAPK signaling pathways and NSD1 gene relationships. Due to this unusual clinical condition, it is important to report such cases and find common points to help understand the etiology. Besides, future comprehensive studies of pubertal development in patients with SS will help to explore the pathophysiological relevance of mechanisms underlying the precocious onset of puberty in these disorders.

Although some cases have been challenging to manage with standard doses, GnRH analog treatment effectively controls CPP in most cases (21). In our case, GnRH analog treatment at high doses could not effectively control the CPP, so CPA was added to therapy. CPAs have both anti-gonadotropic and anti-androgenic features. In addition to blocking the GnRH analogs initial stimulatory effect on the pituitary somatotrophs, CPA has anti-androgenic activity, partly due to its adrenocorticotropic hormone suppressing activity but also to a direct antiandrogen effect (22). Over 20 months of treatment with GnRH analog, the patient's basal LH was $1.6 \mathrm{mIU} / \mathrm{mL}$, basal testosterone level $58 \mathrm{ng} / \mathrm{dL}$, and his bone age advanced to 4.5 years. Due to this pubertal progression and unsuccessful suppression of the LH-testosterone level, CPA $50 \mathrm{mg} /$ day was added to treatment. CPA is a beneficial therapy in CPP therapy with gonadotropin suppressing and 
androgen inhibiting effects, which was not controlled by standard GnRH analog treatment.

Over the next three years with combined treatment, the patient's clinical and laboratory progression was finally controlled. CPA may have adverse effects, mainly in adults and with high doses (20). We found no alterations in liver function tests, despite routine checking, during three years of experience with CPA.

\section{Conclusion}

In conclusion, CPP can very rarely accompany SS, and overgrowth can be related either to the SS itself or the PP. Treatment can also be very challenging, requiring high dose GnRH analog and possibly the addition of CPA. Also, The addition of CPA in this case helped control pubertal progression. Although the etiology of CPP in SS is unknown, it may be related to mutation characteristics of NDS1 or other underlying reasons that will require further clinical evidence.

\section{Ethics}

Informed Consent: Informed consent was received from his parents.

Peer-review: Externally peer-reviewed.

\section{Authorship Contributions}

Concept: Tuğba Kontbay, Zeynep Şıklar, Merih Berberoğlu, Design: Zeynep Şıklar, Merih Berberoğlu, Data Collection or Processing: Tuğba Kontbay, Zeynep Şıklar, Analysis or Interpretation: Tuğba Kontbay, Zeynep Şılar, Serdar Ceylaner, Merih Berberoğlu, Literature Search: Tuğba Kontbay, Zeynep Şıklar, Writing: Tuğba Kontbay, Zeynep Şılar, Serdar Ceylaner.

Financial Disclosure: The authors declared that this study received no financial support.

\section{References}

1. Tatton-Brown K, Douglas J, Coleman K, Baujat G, Cole TR, Das S, Horn D, Hughes HE, Temple IK, Faravelli F, Waggoner D, Turkmen S, Cormier-Daire V, Irrthum A, Rahman N; Childhood Overgrowth Collaboration. Genotype-phenotype associations in Sotos syndrome: an analysis of 266 individuals with NSD1 aberrations. Am J Hum Genet 2005;77:193-204. Epub 2005 Jun 7

2. Edmondson AC, Kalish JM. Overgrowth Syndromes. J Pediatr Genet 2015;4:136-143. Epub 2015 Sep 25

3. Tatton-Brown K, Douglas J, Coleman K, Baujat G, Chandler K, Clarke A, Collins A, Davies S, Faravelli F, Firth H, Garrett C, Hughes H, Kerr B, Liebelt J, Reardon W, Schaefer GB, Splitt M, Temple IK, Waggoner D, Weaver DD, Wilson L, Cole T, Cormier-Daire V, Irrthum A, Rahman $\mathrm{N}$; Childhood Overgrowth Collaboration. Multiple mechanisms are implicated in the generation of $5 \mathrm{q} 35$ microdeletions in Sotos syndrome. J Med Genet 2005;42:307-313.

4. Kurotaki $\mathrm{N}$, Imaizumi $\mathrm{K}$, Harada $\mathrm{N}$, Masuno $\mathrm{M}$, Kondoh $\mathrm{T}$, Nagai $\mathrm{T}$, Ohashi H, Naritomi K, Tsukahara M, Makita Y, Sugimoto T, Sonoda T, Hasegawa T, Chinen Y, Tomita Ha HA, Kinoshita A, Mizuguchi T, Yoshiura Ki K, Ohta T, Kishino T, Fukushima Y, Niikawa N, Matsumoto N. Haploinsufficiency of NSD1 causes Sotos syndrome. Nat Genet 2002;30:365-366. Epub 2002 Mar 18

5. Kamimura J, Endo Y, Kurotaki N, Kinoshita A, Miyake N, Shimokawa O, Harada N, Visser R, Ohashi H, Miyakawa K, Gerritsen J, Innes AM, Lagace L, Frydman M, Okamoto N, Puttinger R, Raskin S, Resic B, Culic V, Yoshiura K, Ohta T, Kishino T, Ishikawa M, Niikawa N, Matsumoto N. Identification of eight novel NSD1 mutations in Sotos syndrome. J Med Genet 2003;40:e126.

6. Baujat G, Cormier-Daire V. Sotos syndrome. Orphanet J Rare Dis 2007;2:36.

7. Visser R, Landman EB, Goeman J, Wit JM, Karperien M. Sotos syndrome is associated with deregulation of the MAPK/ERK-signaling pathway. PLoS One 2012;7:e49229. Epub 2012 Nov 14

8. Bertelloni S, Baroncelli GI, Tomasi O, Sorrentino MC, Costa S, Saggese G. Sindrome di Sotos: follow-up di un caso con pubertà anticipata [Sotos syndrome: follow-up of a case with precocious puberty]. Pediatr Med Chir 1995; 17:353-357.

9. Lim S. Central precocious puberty in a case of SOTOS syndrome (abstract). In: 53rd Annual Meeting of the European Society for Paediatric Endocrinology (ESPE). Dublin, Ireland, September 18-20, 2014: Horm Res Pediatr 2014;82:1-507.

10. Gupta S, Dayal D. Precocious Puberty in an Infant with Sotos Syndrome. Indian Pediatr 2019;56:516.

11. Nagai T, Matsumoto N, Kurotaki N, Harada N, Niikawa N, Ogata T, Imaizumi K, Kurosawa K, Kondoh T, Ohashi $\mathrm{H}$, Tsukahara M, Makita Y, Sugimoto T, Sonoda T, Yokoyama T, Uetake K, Sakazume S, Fukushima Y, Naritomi K. Sotos syndrome and haploinsufficiency of NSD1: clinical features of intragenic mutations and submicroscopic deletions. J Med Genet 2003;40:285-289.

12. Niikawa N. Molecular basis of Sotos syndrome. Horm Res 2004;62 Suppl 3:60-65

13. Wannes S, Elmaleh-Bergès M, Simon D, Zénaty D, Martinerie L, Storey C, Gelwane G, Paulsen A, Ecosse E, De Roux N, Carel JC, Léger J. High prevalence of syndromic disorders in patients with non-isolated central precocious puberty. Eur J Endocrinol 2018;179:373-380.

14. Laccetta G, Moscuzza F, Michelucci A, Guzzetta A, Lunardi S, Lorenzoni F, Ghirri P. A Novel Missense Mutation of the NSD1 Gene Associated with Overgrowth in Three Generations of an Italian Family: Case Report, Differential Diagnosis, and Review of Mutations of NSD1 Gene in Familial Sotos Syndrome. Front Pediatr 2017;5:236.

15. Argyropoulou MI, Kiortsis DN. MRI of the hypothalamic-pituitary axis in children. Pediatr Radiol 2005;35:1045-1055. Epub 2005 Jun 1

16. Mogensen SS, Aksglaede L, Mouritsen A, Sørensen K, Main KM, Gideon $\mathrm{P}$, Juul A. Pathological and incidental findings on brain MRI in a singlecenter study of 229 consecutive girls with early or precocious puberty. PLoS One 2012;7:e29829. Epub 2012 Jan 12

17. Kota AS, Ejaz S. Precocious Puberty. 2019 Nov 18. StatPearls [Internet]. Treasure Island (FL): StatPearls Publishing.

18. Tidyman WE, Rauen KA. Noonan, Costello and cardio-facio-cutaneous syndromes: dysregulation of the Ras-MAPK pathway. Expert Rev Mol Med 2008;10:e37.

19. Zenker M. Clinical manifestations of mutations in RAS and related intracellular signal transduction factors. Curr Opin Pediatr 2011;23:443451. 
20. van der Kaay DC, Levine BS, Doyle D, Mendoza-Londono R, Palmert MR RASopathies Are Associated With Delayed Puberty; Are They Associated With Precocious Puberty Too? Pediatrics 2016;138:e20160182.

21. Carel JC, Eugster EA, Rogol A, Ghizzoni L, Palmert MR; ESPE-LWPES GnRH Analogs Consensus Conference Group, Antoniazzi F, Berenbaum S, Bourguignon JP, Chrousos GP, Coste J, Deal S, de Vries L, Foster C, Heger S, Holland J, Jahnukainen K, Juul A, Kaplowitz P, Lahlou N, Lee
MM, Lee P, Merke DP, Neely EK, Oostdijk W, Phillip M, Rosenfield RL, Shulman D, Styne D, Tauber M, Wit JM. Consensus statement on the use of gonadotropin-releasing hormone analogs in children. Pediatrics 2009;123:e752-e762. Epub 2009 Mar 30

22. Laron Z, Kauli R. Experience with cyproterone acetate in the treatment of precocious puberty. J Pediatr Endocrinol Metab 2000;13 Suppl $1: 805-810$ 